\title{
Process of Mathematical Representation Translation from Verbal into Graphic
}

\author{
Dwi Rahmawatia,b, Purwanto ${ }^{a}$, Subanji ${ }^{a}$, Erry Hidayanto ${ }^{a}$, Rahmad \\ Bustanul Anwar

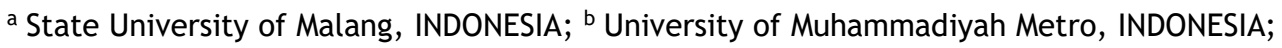

ABSTRACT

The ability to do translation from one form of representation to another representation form is a fundamental ability to build a conceptual and mathematical thinking. Related to the important of translation process, this study aimed to investigate the process of mathematical representation translation from verbal to graph. This research was a qualitative research. Collecting data was done through the assignment sheet and interviews after the subjects completed the task given. The result showed that the students were able to do the process of translation from verbal representation to graph well at every stage of the translation. The translation process was done in four stages: unpacking the source, preliminary coordination, constructing the targets, and determining equivalence. The translation process of verbal to graph representations required more than one translation process. This process through the intermediary of some other representations like symbolic, schematic, equations, numerical. In general, students do the same activity except at preliminary coordination activity. Preliminary coordination activity can be done in two ways, namely students determined the formula of the relationship between distance and time, and by connecting the distance between the two cars and the increasing time. The more the time increased, the distance the two cars decreased.

KEYWORDS

translation process; verbal representation, grahical representation
ARTICLE HISTORY

Received 26 September 2016 Revised 13 November 2016 Accepted 11 February 2017

\section{Introduction}

Representation is one of the five standards of mathematical processes besides problem solving, reasoning, connections and communication stated in Principles and standards for school mathematics (NCTM, 2000). While in

\section{CORRESPONDENCE Dwi Rahmawati dwirahmawati1083@gmail.com}

\section{(c) 2017 Dwi Rahmawati et al.}

Open Access terms of the Creative Commons Attribution 4.0 International License apply. The license permits unrestricted use, distribution, and reproduction in any medium, on the condition that users give exact credit to the original author(s) and the source, provide a link to the Creative Commons license, and indicate if they made any changes. (http://creativecommons.org/licenses/by/4.0/) 
Indonesia the idea of representation has also been included in the objectives of learning mathematics at schools. Representation as one of the mathematical process standards indicates that representation is an important process that the representation in learning to develop and optimize students' thinking skills, which is a process of construction and abstraction of mathematical knowledge. To think mathematically and communicate the mathematical ideas, it needs to represent in various forms of representations such as verbal representation, images, numeric, symbols, algebra, tables and graphs. The use of various types of representation and translation between representations is very important in expressing mathematical ideas (Bal, 2015).

The use of various representations have an important role in learning mathematics (Cai \& Lester, 2005), especially in helping to understand and interpret the mathematical concepts in a variety of representations (Pape \& Tchoshanov, 2001). This is in line with Tripathi (2008) that says in mathematics, the use of multiple representations is an important tool that allows students to understand mathematical concepts. However, generally in mathematics, representation is only as complementary in solving mathematical problems. This leads to a very limited ability representation. The weakness of mathematical representation capability is due to the difficulty in bridging the representations and change from one representation to another representation (Yerushalmy, 1997). Thus, the use of representation deserves serious attention in learning.

Some experts have devided representation in a different way (Bruner, 1966; Lesh et al, 1987; Goldin, 2002; Cai \& Lester, 2005; Gagatsis \& Elia, 2004; Villeges et al, 2009). From some classifications, representations covered in this study are verbal and graphic representations.

Representation as a standard process, NCTM determines the standard of representation that can be mastered in learning is being able to select, implement and conduct translation inter mathematical representations to solve problems (NCTM, 2000). Fluency in doing translation from one form of representation to another representation form is a fundamental ability to be possessed to build a conceptual and mathematical thinking. NCTM (2000) identifies the ability to translate inter mathematical representations as a critical ability in learning and math activities. If students can do the translation inter forms of representation, it means students have access to the representation forms. The more complete the translation ability of the students have, the stronger the understanding of mathematical ideas they have. Through translation capability inter representation done by the students, teachers can see the understanding of the concept. Therefore it is very important for teachers to know the process of translation inter representations done by the students. Teachers need to understand how students perform translation inter representations to be able to track the location and type of errors made by the students when doing translation. Mistakes made by students can be a source of information to improve learning. It is also very important for students as pre service teachers to be able to do the translation inter representations.

Janvier (1987) suggests that translation as a process involving transfer / change from one representation form to other forms of representation. While Bosse et al (2012) state that translation as a cognitive process in transforming information from one representation form to another representation form. Translation activities from one representation to another representation are 
very important in the learning process (Duval, 2006). The translation ability inter representation of graphs, tables, symbolic and verbal is essential in understanding and communicating on mathematical concepts (Bosse, 2011). However, the reality shows that the ability of translation inter verbal representations, tables, graphs and symbolic in mathematical relation is still low (Gagatsis \& Shiakalli, 2004). Students have a difficulty in determining the symbolic representation that is appropriate with the relationship represented in graphs or tables (McCoy, 1996).

The previous research linked to mathematical representation translation has been done at all levels of education, both at the secondary and higher education. Ipek \& Okumus (2012) who did a research on prospective primary school teachers in the use of representation in the problem solving process state that prospective teachers are not able to do the translation inter representations. Celik \& Arslan (2012) conducted a study on pre service teachers of primary school to determine the ability of students' translation among verbal representations, tables, graphs and physical context. In the research they found that the students have not been able to do the translation in the types of representation, particularly that of the physical context to the graph. Students are more successful in determining the correct graph rather than constructing a graph. While Bal (2015) in a study conducted on 134 pre service teachers of primary school in state university in Turkish found that students are usually successful in the transformation inter representation, but do not succeed in the transformation particularly verbal representation to another representation. The success of students in solving problems is most in symbolic representation and the least is in verbal representation. The students state that the different forms of representation help to understand the problem better and produce some solutions. Bal suggests that the next study should examine the process of translation between representation and various forms of representation in problem solving.

Bosse et al (2014), in their study on students of 15 to 17 years old found that there are four activities done by the students in doing translation from the graph to the symbolic. The activities are unpacking the source, preliminary coordination, constructing the targets, and determining equivalence. Bosse suggests that further studies, about mathematical representation translation besides from the graph to the symbolic, are also needed in completing the research to examine in more detail in the translation process.

Related to the previous study, the result of this study will describe the process of translation from verbal representation to grahical representation. The results of this study are expected to be used to reflect and evaluate the translation process in the forms of representations as the consideration in arranging appropriate learning.

\section{Research Method}

This study aimed to reveal the translation process from verbal representation to the graph. To reveal the translation process of the research subjects, this research was conducted by asking the research subjects to resolve the problem in writing and expressing verbally. Translation process was seen from the behavior subject to resolve problems based on translational activity (Bosse, 2014). In this study, the researcher was as a means to collect data, analyze data descriptively in the form of behavior words experienced by the 
subject. According to Cresswell (2012) this research was qualitative research. The subjects in the study were students of mathematics education. Subjects were asked to solve the problem. The researcher chose two from ten students as subjects. The research subject was selected by taking into account the work result and communication skill.

The instrument of this study was the researcher guided by the assignment sheet. The researcher acted as the instrument that collected data, analyzed the data, interpreted the data and reported the results. The work sheet Instruments used was the development of assignment sheet (Celik \& Arslan, 2012). The assignment sheet is as follows:

Car A goes from town $\mathrm{X}$ to town $\mathrm{Y}$ at a steady pace. Car B goes from town $\mathrm{Y}$ to town $\mathrm{X}$ at a constant speed. Both cars go at the same speed, time and route. Draw a graph showing the relationship between the distance of the two cars on the travel time! Give an explanation for your answer!

The data in this study were words and note of the behavior of the research subjects when solving a given problem. Data were obtained from the written answers and field notes when the subject solved the problem. Field notes were the notes of behavior and verbal statement recorded when the subject resolved a given problem. The result of the interview was in the form of clarification of the subject's written answer.

Based on the research objective, qualitative data analysis technique was used in this study. The researcher analyzed every word, action and the student's written responses related to problems solving produced by the subject. The data analysis included the steps of transcribing the data collected, analyzing and reducing the data, compiling every piece of data in units which were then encoded, analyzing the translation process and making conclusions. Analyzing data was conducted during the research when data retrieval simultaneously or after retrieval of data.

\section{Results and Discussion}

The research subject was given a problem presented in verbal form. Subject was asked to perform the translation from mathematical representation verbal to graph. In general, based on the translation activity proposed by Bosse (2014), the research subject did the process of mathematical representations translation from verbal to graphics through four activities. The activities were unpacking the source, preliminary coordination, constructing the targets, and determining equivalence. The process of translation in four activities undertaken by research subject is as follows:

Subject S1

The first activity was unpacking the source. After facing with the problem, S1 could instantly know the important words related the problem. He was able to understand the essential ideas in a verbal representation problem. It indicated that $\mathrm{S} 1$ was able to perform unpacking the source activities well. S1 behavior when performing unpacking the source was he read the problem given repeatedly and marked the words that were considered important by underlining the words on a given problem. S1 revealed the verbal representations given by identifying the components in verbal representations namely the same time, the distance of the two cars, mileage car, same speed, constant speed, distance of city X \& Y and direction. Next the components of the verbal representations were translated into the components forming graphic 
images. Here are the excerpts of interviews related to the activity of unpacking the source:

$P$ : What information do you get from the problem?

$S 1$ : here there are car $A$ and $B$ running at the same speed and constant, $V$ ${ }_{A}=V_{B}=V$, then car $A$ and $B$ go in the opposite direction like this (pointing to the scheme that has been made), car $A$ and $B$ run in the same time so that the travel time is the same.

$P$ : Why do you make this schema?

S1: to help me describe the event ma'am.

$P$ : Okay. Then is there information that you do not understand?

S1: there is no ma'am.

P: Do you understand the question on the problem? Explain, please.

S1: Yes ma'am, here I was told to draw a graph of distance between the two cars towards the time.

$P: I_{S}$ the information enough to answer the questions?

S1: Yes ma'am.

Interview result showed that $\mathrm{S} 1$ was able to recognize all of the information in the sentence that could be used to solve the problem, identify the key words that declared the information in the source representation and understand the questions. It means that $\mathrm{S} 1$ had conducted unpacking the source activities well to solve the problem.

To obtain a graph component, first S1 did the coordination preliminary activities. The second activity was done by S1 smoothly. S1 was able to connect the literature to formulate a target representation and transfer the content of the source representation into the target representation. S1 was able to connect the information that had been identified with the understood concept. It showed that $\mathrm{S} 1$ was able to choose any elements that need to be exemplified and select the symbol used. S1 changed the verbal component in the form of speed, distance and time through analogy with formal symbols. For verbal component within the two cars, $\mathrm{S} 1$ expressed it by symbol $\mathrm{x}$. The verbal component of constant speed and distance of city $\mathrm{X}-\mathrm{Y}$ was expressed as $\mathrm{V}$ and $\mathrm{y}$. While the verbal component in the form of directions, S1 changed it by making schema that indicated the travel direction of both cars from city A and B. Based on the schemas that had been made, $\mathrm{S} 1$ determined the interval. The problem solving of $\mathrm{S} 1$ when creating the schema can be seen below:
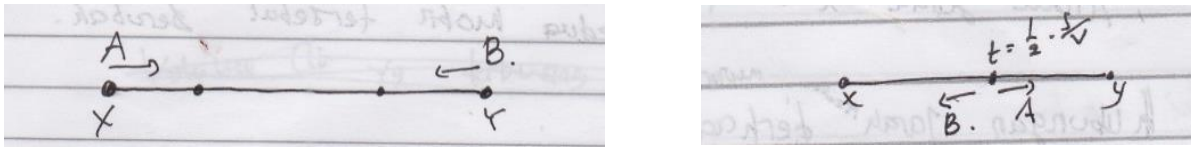

Figure 1. Answer S1 while Unpacking The Source by Creating a Schema

S1 then set up information that might be used to construct the target representations. S1 connected inter verbal component that had been declared symbolically and schematically to form the mathematics equation by performing a series of algebraic operations to obtain the relationship between the distance of the two cars towards the time. S1 associated it with the formula of distance, speed and time he had. It showed S1 was able to create networks and the idea relationship of inter representations, such as statements (Duval, 2006). S1's ability in integrating ideas inter these representations was helpful in the translation stage. By forming this mathematical equation, S1 could earn some coordinate points and the declivity of the graph, so it would help in making the 
graphic images in the next stage of the translation. The mathematical equation formed by $\mathrm{S} 1$ is $x=\begin{aligned} & y-2 t \cdot v ; 0 \leq t \leq \frac{1 \mathrm{y}}{2 V} \\ & 2 t \cdot v ; t>\frac{1 \mathrm{y}}{2 V}\end{aligned}$. Here is the excerpts of the interview: get?

P: How will you draw a graph using the information in the problem you

S1: First of all let's say, $S_{A}$ and $S_{B}$ are the mileage of car $A$ and B. $t_{A}$ and $t_{B}$ are the travel time of car $A$ and $B . y$ is the distance of city $X$ and $Y$, and $x$ is the distance of the two cars. After that I count the distance of two cars: $x=y^{-}(S$ $\left.A+S_{B}\right)=y-(t V+t V)=y-2 t$. V. It is because the travel time and speed of both cars are the same. Well, because the two cars run in the opposite directions (pointing to the schema), then the car will met. So after meeting, the distance is $x=2 T V$.

$P:$ When will the two cars meet?

S1: At $t=\frac{1}{2} \frac{y}{V}$, so $x=\begin{aligned} & y-2 t . v ; 0 \leq t \leq \frac{1 y}{2 V} \\ & 2 t . v ; t>\frac{1 y}{2 V}\end{aligned}$

$P$ : Do you think there is another way to draw graphs?

$S 1: \mathrm{mmm}$... there is no ma'am.

The result of $\mathrm{S} 1$ when doing presuppose (Figure 1) and algebraic operations (Figure 2) preliminary coordination activity is as follows:
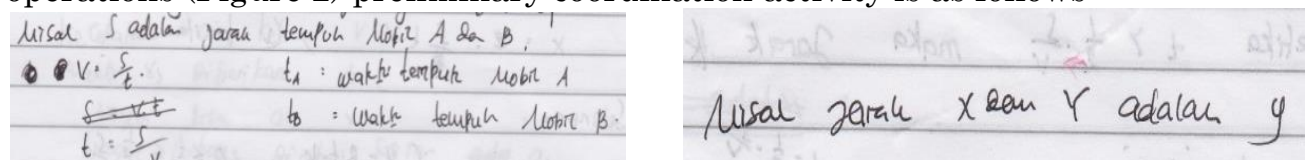

Figure 2. Answer S1 while Preliminary Coordination by Doing Presuppose
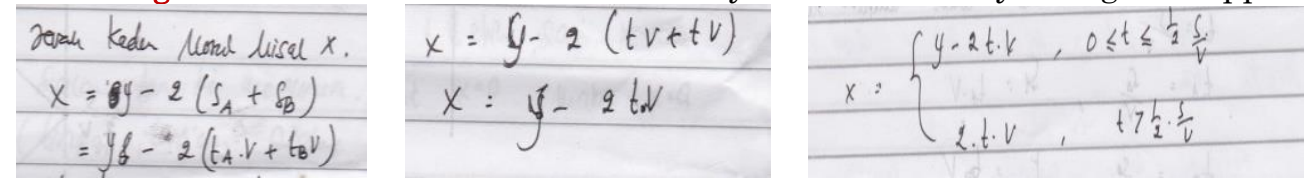

Figure 3. Answer S1 while Preliminary Coordination by Algebraic Operations

In the third activity, S1 did constructing the target well. After S1 symbolizes the verbal component of the distance of both cars with $\mathrm{x}, \mathrm{S} 1$ determined $\mathrm{x}$ as the $\mathrm{X}$-axis that was as component of the graph while the verbal component of the time represented by symbol t became the graph component namely $\mathrm{Y}$-axis. Then by linking $\mathrm{T}, \mathrm{V}$ and $\mathrm{Y}$ based on the concept already understood, $\mathrm{S} 1$ determined the range members namely 0 and $\frac{1}{2} \frac{\mathrm{y}}{\mathrm{V}}$. For the graph components as domain member, $\mathrm{S} 1$ acquired it from the verbal component of distance of XY city by turning it into symbol y first. Domain members obtained were 0 and $\mathrm{y}$. By using the equations that had been obtained, S1 determined the coordinate points which were the component maker of graphic images. S1 substituted $t$ as the range members that fulfilled the equation. He obtained coordinates of point $\left(0, \frac{1}{2} \frac{\mathrm{y}}{V}\right)$ and $(\mathrm{y}, 0)$. Then, based on the equation and interval obtained in the preceding stage, S1 determined the graph gradient namely where the graph had a declivity to the right or left.

Based on the graphs maker components obtained, S1 made a sketch of each graph maker component. First of all S1 sketched X axis as $\mathrm{x}$, then the Yaxis as t. Then $\mathrm{S} 1$ put the domain member on the $\mathrm{X}$ axis and the range member 
on $\mathrm{Y}$ axis with the right scale. $\mathrm{S} 1$ then described each pair of points obtained and then draw a line connecting the pair of points on the Cartesian coordinate plane. Here are the excerpts of interview:

$P$ : What do you do to draw a graph that corresponds to the problem after you obtain the formula?

S1: The graphics is made by determining $s b-X$ as the distance of the two cars nemely $\mathrm{x}, s b-Y$ as the travel time namely $t$, then for example for $t=0$ then $\mathrm{x}$ $=y$, and for $x=O$ then $t=\frac{1}{2} \frac{y}{V}$. Then I draw it like this (pointing to the picture). targets:

Here is the result of $\mathrm{S} 1$ problem resolution when doing constructing the

Figure 4. Answer S1 when Doing Constructing the Target

In the fourth activity namely determining equivalence, $\mathrm{S} 1$ checked all the steps that had been done and recalculated the answers that had been obtained. S1 discovered again if there was no error in the operation or not. Then he rechecked the graph suitability with the information existed in the verbal representation (source). The excerpts of the interview are as follows:

$P$ : Are you sure with your answer?

S1: yes, I have rechecked it, Ma'am. please.

P: How do you check that the graph you are getting correct? Explain,

S1: this is at $t=0$, then the distance between the two cars are the same as the distance of city $X$ and $Y$ namely $y$, the two cars meet at $t=\frac{1}{2} \frac{y}{V}$ so that the distance is $O$.

Here is the structure of the translation process done by $\mathrm{S} 1$ based on the activity of translation:

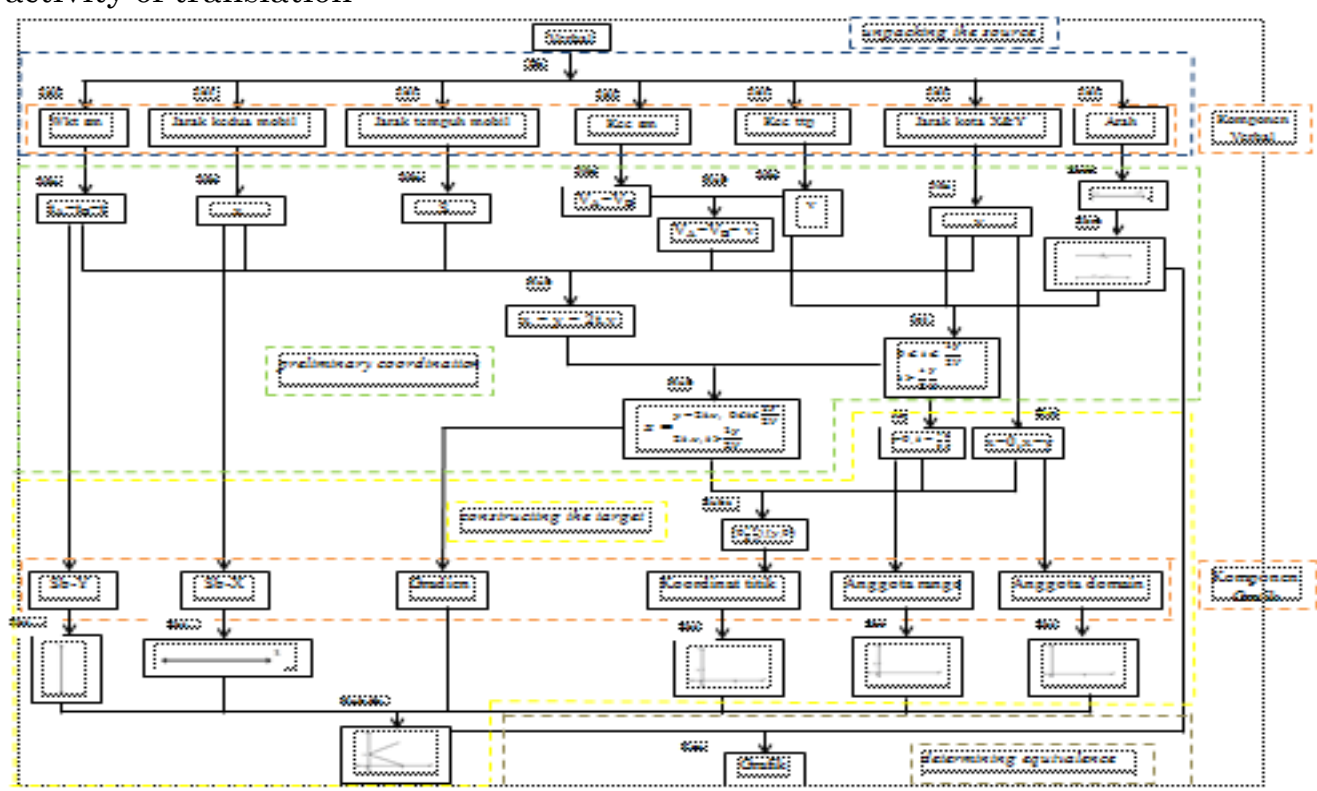


Figure 5. Structure of Translation Process by S1

Table 1. Description of the coding on the process of verbal representations translation to the graph by $\mathrm{S} 1$

\begin{tabular}{ll}
\hline Term & Code \\
\hline Verbal representation & Verbal \\
Reading matter & $\mathrm{Bc}$ \\
Identify & Idf \\
Presuppose & Mis \\
Connect & Hub \\
Decide variables sb-X and sb-Y & Sb \\
substitute the value & Subs \\
Determine the gradient & Gr \\
Check the suitability of the graph & Kes \\
A car speed of A equal to the speed of car B & Kec sm \\
The travel time of car A equal to travel time of car B & Wkt sm \\
Car A runs from city X to Y, car B runs from city Y to X & Skm \\
Speed of Car A and B constant & Kec tetap \\
Speed of car A, the speed of car B, travel time of car A, travel time of car B, distance V A, V B, t A, t \\
between car A and B, the distance between city X and Y, the speed of the car, car B, X, y, v, t \\
travel time & Hub ttk \\
Connect the dots & Int \\
Determine the interval & Dm \\
Determine domain member & Rn \\
Determine range members & Kt \\
Determine the point coordinates & Skt \\
Sketch & Grafik \\
Graphic representation & P
\end{tabular}

Based on the structure process of the verbal representations translation to the graph above, $\mathrm{S} 1$ unpacked source in the form of verbal representations given by identifying the components of the same time, the distance of the two cars, mileage car, same speed, constant speed data, the distance of city X \& Y and direction. Each component of verbal was translated into components of graph maker to illustrate the graph that corresponded to the verbal representation. The components forming the graphic of the translation result of verbal component made by $\mathrm{S} 1$ in the form of the $\mathrm{X}$ axis, $\mathrm{Y}$ axis, point coordinates, a member of a domain, range members and gradients. To make the process of translation from verbal problem into a graph, $\mathrm{S} 1$ required intermediaries of some representations such as symbolic, equations, schema and numeric.

$\mathrm{S} 1$ drew the graph by connecting all the components to make graphics that had been obtained. S1 created cartesian coordinate with $\mathrm{x}$ as the $\mathrm{X}$-axis and $\mathrm{t}$ as $\mathrm{Y}$ axis. Then $\mathrm{S} 1$ put the domain members and range on the coordinate axes. Next, S1 made a point for each pair of points obtained and then drew a line connecting the points couple with due regard to the gradient.

\section{Subject S2}

Based on the answers of S2 when solving problems, it showed that S2 was able to resolve the problem properly. For the first activity, S2 did unpacking the source by understanding the problem well, finding things that were considered important in a given problem. S2 had been able to recognize all the information in the sentence that could be used to solve the problem, identify key words that declared that the information on the source representation and understand the questions. S2 revealed the verbal problem by identifying verbal components that 
existed on the source problem. Some verbal components were time, the same time, the distance of the two cars, car mileage, same speed, constant-speed, the distance of city X \& Y and direction. These verbal components which would then be translated into a graph would be the component forming graph, which would be used in creating graphic images. S2 had been able to identify all the components needed. It meant S2 had conducted unpacking the source well to solve the problem. Here are the excerpts of the interview:

$P$ : What information do you get from the problem?

S2: The speed of car $A$ and $B$ is same and constant, $V_{A}=V_{B}$. Car $A$ and $B$ run at the same time, car $A$ runs from city $X$ and $Y$, car $B$ runs from town $Y$ to $X$ like this (showing a picture)

$P$ : Are you familiar with the information?

S2: yes

$P:$ Do you understand the question on the matter? Explain, please.

S2: yes, it is asked the graph relationship between the distance of the two cars towards the time.

$P:$ Is there enough information to answer questions?

S2: Yes, there is.

In the second activity, S2 was able to perform preliminary coordination activity by linking literature to formulate a target representation and transfer the content of the source representation into the target representation. S2 was able to choose any elements needed to be exemplified and select the symbol used. It showed S2 performed analogy of verbal component in the form of distance of city X \& Y, time, speed, distance between the two cars, car mileage by conducting symbolization $\mathrm{S}, \mathrm{t}, \mathrm{v}, \mathrm{S}$ i, $\mathrm{S}_{\mathrm{Ai}}, \mathrm{S}$ Bi formally. It meant he was able to connect information that had been identified with the concept understood. For the verbal component of directions, S2 made the schema related to travel direction of the two cars. The result of S2 completion while doing analogy (Figure 5) and making the schema (Figure 6) related to the travel direction is as follows:

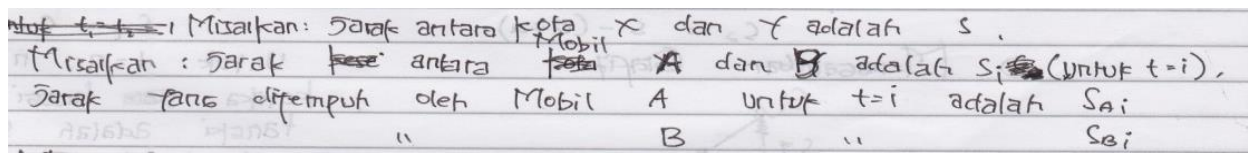

Figure 6. Answer S2 while Preliminary Coordination by Doing presuppose

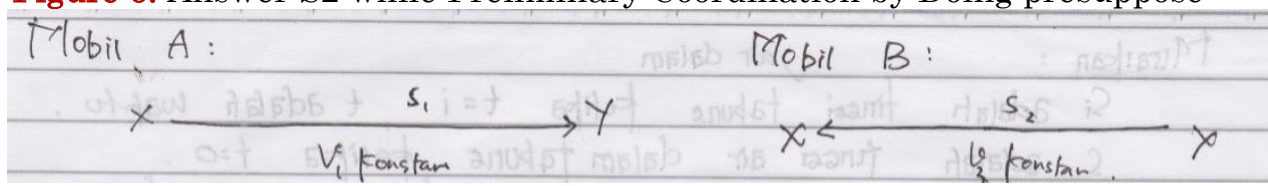

Figure 7. Answer S2 while Preliminary Coordination by Making Schema

S2 connected the time change towards the distance of the two cars where the speed of both cars was constant. S2 performed a series of algebraic operations to determine $\mathbf{S}_{i}$ and defining a relationship between $\mathbf{S}_{0}, \mathbf{S}_{1}, \mathbf{S}_{2}, \mathbf{S}_{3}$ etc. $\mathrm{S} 2$ created patterns between the distance of the two cars if $t$ increased more. $\mathrm{S} 2$ started at $\mathrm{t}=0$, the result was $\mathrm{S} 0=\mathrm{S}$ that was when $\mathrm{t}=0$ the result was the distance of the two cars equal to the distance of the city $\mathrm{X}$ and $\mathrm{Y}$. Then S2 replaced $\mathrm{t}$ with $1,2,3$ and so on. Thus the result was pattern that the more the time increased, the smaller the distance of the two cars. The distance the two 
cars would be 0 when two cars met, then it would increase gradually. Here is the excerpt of the interview:

P: How will you draw a graph using the information in the questions you get?

S2: by exemplifying: $S$ is the distance between the car $A$ and $B$ for $t=i, S$ $A i$ is the distance traveled by car $A$ for $t=i, S_{B i}$ is the distance traveled by car $B$ for $t=i$. The distance between city $X$ and $Y$ is $S$. Both cars run at the same time, then $t_{A}$ and $t_{B}$ are equal because $V_{A}=V_{B}$ and $t_{A}=t_{B}$ then $S_{A}=S_{B}$. For determining $S_{i}$ (distance of the two cars) for some value of $t$ (travel time).

For $t=0$, then $S_{O}=S-\left(S_{A O} B O+S\right)=S$

For $t=1, S_{1}=S-\left(S_{A 1}+S_{B 1}\right)$

For $t=2$ then $S_{2}=S-\left(S_{A 2}+S_{B 2}\right)$

For $t=3$ then $S_{3}=S-\left(S+S_{A 3-B 3}\right)$

For $t=n, n$ is the time when $S_{i}=0$, that is $S+S S_{A i B i}=S$

$P$ : When $t=n$ ?

$Y$

S2: When car $A$ and $B$ meet, when running halfway distance of city $X$ and

$P:$ How is the relationship between $S 0, S 1, S_{2}$ and so on?

$S 2: S O>S 1>S 2>\ldots>S n=0$

$P$ : Why is that?

S2: because $S_{A i}=S_{B i}$ and $S_{A 1}<S_{A 2}<S_{A 3}$ so that $S O>S 1>S 2>\ldots>S n$

Here is the result of the problem completion by $\mathrm{S} 2$ at the time of preliminary coordination:

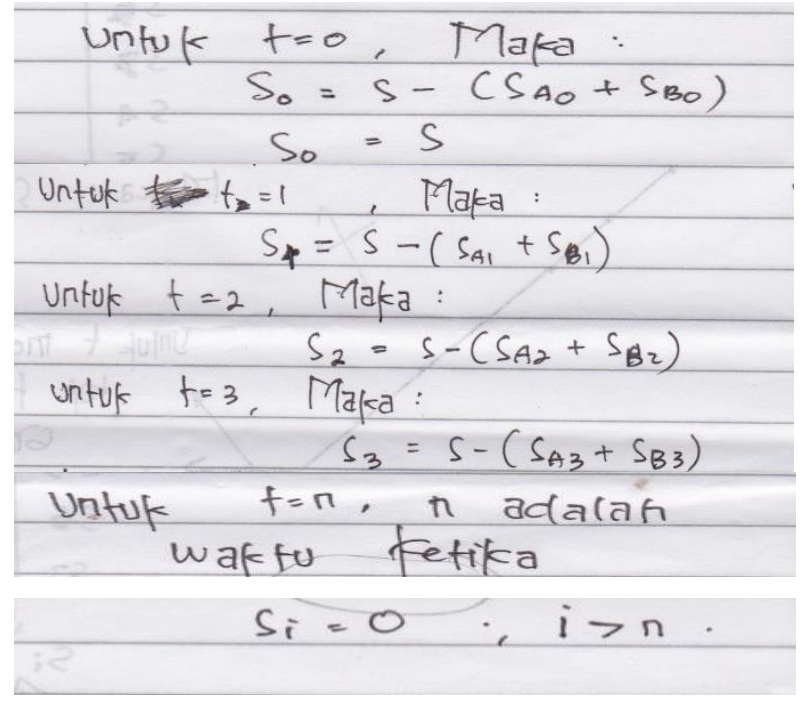

Figure 8. Answer S2 while Preliminary Coordination by Algebraic Operations

For the third activity, S2 did constructing the target by specifying $\mathrm{Si}$ as the $\mathrm{X}$-axis and $\mathrm{t}$ as $\mathrm{Y}$-axis to state time. From the calculation of $\mathrm{Si} \mathrm{S} 2$, it was stated that S0, S1, S2, S3 and so on were the members of the range in the graph. Similarly to the graphics component in the form of domain member, expressed numerically $0,1,2$, and so on as the domain members. Based on the pattern obtained, S2 determined the points coordinate as the components forming graph. They were $(0, \mathrm{~S} 0),(1, \mathrm{~S} 1),(2, \mathrm{~S} 2),(3, \mathrm{~S} 3)$ and so on. Based on the relationship of $\mathrm{S} 0>\mathrm{S} 1>\mathrm{S} 2>\mathrm{S} 3>\ldots>\mathrm{Sn}$ and $\mathrm{Sn}<\mathrm{Sn}+1<\mathrm{Sn}+2<\ldots, \mathrm{S} 2$ stated verbally that 
graph of $t=0$ moved from the top down, then it moved from the bottom up upward. This verbal statement was a graphic component of gradient.

After the components forming the graph were obtained, S2 made Cartesian coordinate with $\mathrm{t}$ as $\mathrm{X}$-axis and $\mathrm{S}_{\mathrm{i}}$ as $\mathrm{Y}$-axis. Then he put the domain member and range at the correct scale. S2 marked points on the coordinate plane which was the location of points coordinate obtained. Furthermore S2 drew the graph by connecting the points that had been put up and took notice of the movement. S2 drew graphs with pictures starting from $t=0$ (sb-small X), moved from the top down with the declivity to the left, then the graph moved up to the top with a declivity to right. Here's the interview:

$P$ : What do you do to draw a graph that corresponds to the problem?

S2: First I determine that sb-X states the travel time, $s b-Y$ represents the distance of the two cars in Cartesian coordinates. Then I draw a graph starting from $t=O(s b$-small $X)$, moving from the top down and moving bottom up as like this (pointing to the picture)

$P$ : Have you had improved the graph that you have created? Explain, please.

S2: yes ma'am, I forgot that car $A$ and $B$ after meeting are still running so it will repel each other so that the distance of both enlarge like this (pointing to the picture)

The fourth activity is determining equivalence, $\mathrm{S} 1$ checked all the steps that had been done and recalculated the answer. S1 searched if there was an error in the operation or not. Then he checked the suitability of graph with the information in verbal representation (source). After rechecking, S2 improved the graphics for he forgot that the cars still ran after the meeting, so the graph changed. The excerpts of the interview are as follows:

$P$ : Are you sure with your answer?

S2: yes.

P: How do you check that you are getting the correct graph? Explain, please.

S2: I reread from the top ma'am

Here is the result of S2's problem solving when performing determining equivalence:

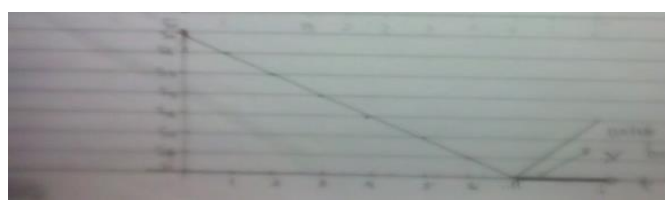

Figure 9. Answer S2 when Perfoming Determining Equivalence

Here is the structure of the translation process done by S2 based on the translation activity: 


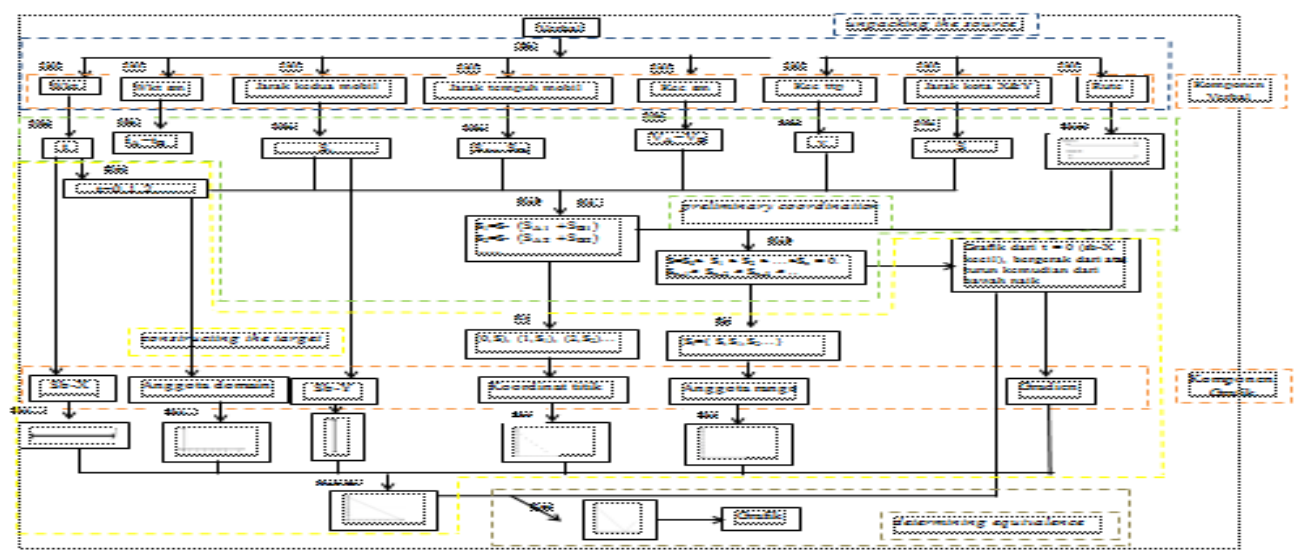

Figure 10. Structure of Translation Process by S2

Table 2. Coding Description on the translation process of verbal representations to the graph by $\mathrm{S} 2$

Term

Code

Verbal representation

Reading matter

$\mathrm{Bc}$

Identifying

Idf

Exemplifying

Mis

Connecting

Hub

Calculating

Hit

Making a schema of car A runs from city X to Y, car B runs from city Y to X

Skm

Determining domain member

$\mathrm{Dm}$

Determining range member

$\mathrm{Rn}$

Determining coordinate points

$\mathrm{Kt}$

Determining the gradient

Gr

Define variable $s b-\mathrm{X}$ and $\mathrm{sb}-\mathrm{Y}$

$\mathrm{Sb}$

Sketching

Skt

Connecting the coordinate points

$\mathrm{Hub}$

Checking the suitability of the graph

ttk

Speed of car A equal to the speed of car B

Kes

Kec

Traveling time

sm

Travel time of car A equals the travel time of car B

Wkt

Speed of Car A and B is constant

Wkt

sm

Kec

ttp

The distance between city $\mathrm{X}$ and $\mathrm{Y}$, speed of car A, speed of car B, travel time, the distance S, V between car $A$ and $B$ when $t=i$, mileage of car $A$ when $t=i$, mileage of $\operatorname{car} B$ when $t=i$ and $A, V B$, speed

Mileage of car A equals the mileage of car B for each $t=i$

$\mathrm{Bi}, \mathrm{V}$

$\mathrm{S}_{\mathrm{Ai}}=$

$\mathrm{S}_{\mathrm{Bi}}$

Graphic representation

Grafik

Translation process of verbal representation to graph done by $\mathrm{S} 2$ through four translation activities (Bosse et al,2014). S2 identified the component of 
verbal representation from the problem given namely time, the same time, the distance of the two cars, car mileage, the same speed, constant speed, distance of city X \& Y and directions. S2 translated the verbal components forming graphic image in the form of $\mathrm{X}$-axis, $\mathrm{Y}$-axis, domain members, range members, point coordinates and gradient. In doing translation, S2 required intermediaries of some representations like symbolic, schematic, numerical and verbal.

Based on the answers, subject S1 and S2 both written and verbal, the results showed that subjects could perform translation process of verbal representation to graph well through four translation activities as stated by Bosse (2014) ie unpacking the source, preliminary coordination, constructing the targets, and determining equivalence. Preliminary coordination could be done by determining the formula of the relationship between distance and time of the event given just as done by subject S1. S2 did it by connecting the distance between the two cars and the increasing time. The more the time increased $(\mathrm{t})$ the less the distance of the two cars are. For other activities in general S1 and $\mathrm{S} 2$ performed the same activity.

Subject S1 and S2 performed the translation process of verbal to graph through intermediaries of some representations. It meant that the translation process of verbal representations to graph needed more than one translation process or in other words translation indirectly (Janvier, 1987) or globally (Duval, 2006). Based on the translation activity, subject showed that the translation process of each subject was different. Translation process has different complexity depending on the activity (Bosse et al, 2011). The process of translation from verbal is the most complex translation process (Bal, 2015; Bosse et al, 2011), therefore it is very important for pre service teachers and teachers know the activity of translation, especially from the verbal to the graph. By knowing the translation process inter representations, it is expected that future pre service teachers and future teachers can improve the ability of students in translation process effectively.

Conclusions and Suggestions

Based on the research that has been done it can be concluded that the students are able to make the process of translation from verbal representations to graph well. Translation process is done in four stages: unpacking the source, preliminary coordination, constructing the targets, and determining equivalence. The subjects did translation in every verbal representation component to graph representation component. The process of translation is from verbal to graph through the intermediary of other representations. Intermediary representation used by each subject is different, so the complexity level of each subject translation process varies depending on the activity performed. The activity of preliminary coordination can be done in two ways, namely students determine the formula of relationship between distance and time of the event given, and by connecting the distance between the two cars and the increasing time. The more the time $(\mathrm{t})$ increases, the less the distance of the two cars is. For the other activities in general students do the same activity. This research is limited only on the verbal representations to the graph. The reverse process, namely the graph to the verbal has not been seen yet. And it does not give attention to the characteristics of the subject deeply as the level of ability that might affect the representation translation process. The limitation in this study has the potential to be studied in further research. 


\section{Disclosure statement}

No potential conflict of interest was reported by the authors.

\section{Notes on contributors}

Dwi Rahmawati - Department of Mathematics Education Doctoral, State University of Malang, Malang, Indonesia; Department of Mathematics Education, University of Muhammadiyah Metro, Metro, Indonesia

Purwanto - Department of Mathematics Education, State University of Malang, Malang, Indonesia

Subanji - Department of Mathematics Education, State University of Malang, Malang, Indonesia

Erry Hidayanto - Department of Mathematics Education, State University of Malang, Malang, Indonesia

Rahmad Bustanul Anwar - Departmen of Mathematics Education, University of Muhammadiyah Metro, Metro, Indonesia

\section{References}

Bal, A. P. (2015). Skills Of Using And Transform Multiple Representations Of The Prospective Teachers. Journal of Mathematical Behavior, 197(Hal.), 582-588.

Bosse, M. J., Gyamfi, K. A\& Chandler, K. (2011). Translation among Mathematical Representation: Teacher Belief and Practices. (Online), (http://www.cimt.org:uk/journal/bosse4.pdf)

Bosse, M. J., Gyamfi, K. A\& Chandler, K. (2012). Lost in Translation: Examining Translation Errors Assosiated with Mathematical Representation. School science and Mathematics, $112(3), 159-170$

Bosse, M. J., Gyamfi, K. A\& Chandler, K. (2014). Students Differented Translation Processes, (Online), (http://www.cimt.plymouth.ac.uk/journal/bosse5.pdf).

Bruner, J. (1966). Towards a theory of instruction. Cambridge, MA: Harvard University Press.

Cai, J., \& Lester, F. K. 2005. Solution representations and pedagogical representations in Chinese and U. S. classrooms. Journal of Mathematical Behavior, 24, 221-237.

Celik, D.\& Arslan, A. S. (2012). The Analysis of Teacher Candidats Translating skill in Multiple Representations, (Online), (http://ilkogretim-online.org.tr/vol11sav1/v11s1m18.pdf $)$.

Creswell, J.W. (2012). Educational Research. Pearson.

Duval, R. 2006. The cognitive analysis of problems of comprehension in the learning of mathematics. Mediterranean Journal for Research in Mathematics Education, 1(2), 1-16.

Gagatsis, A. \& Elia, I. (2004). The Effects of Different Modes of Representation on Mathematical Problem Solving. Proceedings of The 28th Conference of The International Group for The $P M A, 2,447-454$.

Gagatsis, A., \& Shiakalli, M. (2004). Ability to translate from one representation of the concept of function to another and mathematical problem solving. Educational Psychology, 24(5), 645-657. 
Goldin, G. A. (2002). Representational systems, learning, and problem solving in mathematics. Journal of Mathematical Behavior, 17(2), 137-165.

İpek, A. S., \& Okumuş, S. (2012). İlköğretim matematik öğretmen adaylarının matematiksel problem çözmede kullandıkları temsiller. Gaziantep Üniversitesi Sosyal Bilimler Dergis, 11(3), $681-700$.

Janvier, C. (1987). Translation Processes in Mathematics Education. Dalam Janvier(Ed). Problems of Representation in the Teaching and Learning of Mathematics, 27-32, Hillsdale, NJ: Lawrence Erlbaum Associates.

Lesh, R., Post, T., \& Behr, M. (1987). Representations and translations among representations in mathematics learning and problem solving. New Jersey: Lawrence Erlbaum Associates.

McCoy,L.P., et. Al. (1996). Using Multiple Representation to Communicate: an Algebra Challenge. Reston. VA: NCTM

National Council of Teachers of Mathematics. (2000). Principles and Standards for School Mathematics. Reston, VA: NCTM.

National Council of Teachers of Mathematics. 2000. Principles and Standards for School Mathematics. Reston, VA: NCTM.

Pape, S.J.\& Tchoshanov, M.A. (2001). The Role of Representation(s) in Developing Mathematical Understanding. Theory into Practice, 40(2), 118-125.

Tripathi, P. N. (2008). Developing mathematical understanding through multiple representations. Mathematics Teaching in Middle School, 13(89), 438-445.

Villegas, J. L., Castro, E., \& Gutierrez, J. (2009). Representation in problem solving: A case study with optimization problems. Electronic Journal Of Research In Educational Psychology, 7(1), 279-308.

Yerushalmy, M. (1997). Designing Representations: Reasoning about Functions of Two Variables. Journal for Research in Mathematics Education, 27 (4), 431-4. 